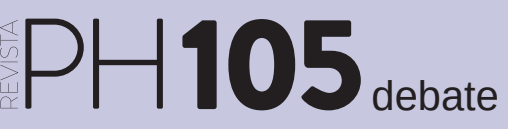

Interpretación y gestión del patrimonio en los espacios del turismo oscuro

coordinan Óscar Navajas Corral y Maribel Rodríguez Achútegui

\title{
La tortura en España: un ejemplo de turismo oscuro
}

Josu Santamarina Otaola | Universidad del País Vasco-Euskal Herriko Unibertsitatea (UPV-EHU)

URL de la contribución <www.iaph.es/revistaph/index.php/revistaph/article/view/5027>

Actualmente hay decenas de museos sobre la tortura en España. En ellos se cuenta cómo las instituciones del Estado han detenido, maltratado y asesinado a cientos de personas en este país. Personas que, por su ideología, credo o forma de vida, han sido vistas como una amenaza para el régimen dominante. Personas que han sido procesadas y ajusticiadas de manera cruenta sin tomar en cuenta en ningún caso lo establecido en documentos internacionales como la Convención Europea de Derechos Humanos (Consejo de Europa, 1950) o la Convención contra la Tortura (1984).

En estos museos se habla de tribunales específicos que dan las órdenes y de hombres armados que ejecutan el mandato de manera expeditiva. Una historia de violencia y represión que se representa de manera muy contundente, sin tapujos, apelando directamente a las emociones de las y los visitantes a través de un aparato museístico espectacular: espacios de encierro, como calabozos y salas de aislamiento; instrumentos y muebles empleados para producir tormento, como sillas, mesas y objetos punzantes; documentos asociados a los procesos judiciales y confesiones sacadas a base de tortura; maniquíes representando diversas formas de castigo y asesinato, etc. Estos museos sobre la tortura suelen formar parte del reclamo turístico de una gran cantidad de localidades y miles -quizá decenas de miles- de personas los visitan cada año. Es posible incluso encontrar a algún que otro grupo escolar o a familias enteras haciendo cola en la entrada de estos espacios expositivos.

Estos museos se sitúan en algunas de las ciudades más visitadas de España, como Barcelona o Toledo. Aunque también pueden encontrarse en pueblos de menor tamaño, lugares en los que se considera que la estampa pintoresca o "de postal" de estas localidades no se ve empañada por la existencia de este tipo de museos sobre la tortura.

Su existencia podría ser vista como un claro y definitivo síntoma de la normalidad política y cultural de España. Una prueba más de la homologación de este país en relación con los estándares europeos. Y es que, hay que señalar que existen espacios similares en ciudades de Europa de primer nivel, como Ámsterdam, Praga o Viena. Aunque hay que decir también que en España esta particular tipología de museo, un claro exponente de un interés social por el "turismo oscuro", tiene un especial predicamento. $\mathrm{Y}$ por ello, sin pretender ser exhaustivo, es posible que España sea el país europeo con mayor cantidad de museos sobre la tortura, siendo un referente a nivel internacional en este ámbito.

Dicho todo esto, hay un elemento que quien lea estas líneas, sobre todo si conoce España, habrá podido entrever ya. Para empezar, en estos museos sobre la tortura no se hace ninguna mención a los tratados internacionales que se han mencionado al principio, ni suele existir ningún tipo de intención didáctica en clave de derechos humanos. En segundo lugar, la espectacularidad de sus propuestas expositivas busca más producir emociones como el morbo, que estimular la empatía, la denuncia colectiva o la reflexión crítica. Incluso hay que decir que algunos de los objetos expuestos a veces se corresponden con instrumentos de tortura cuya utilidad histórica real se halla en entredicho, como la célebre "doncella de hierro", una especie de ataúd metálico con "forma de mujer" y con pinchos en su interior. En tercer y último lugar, por supuesto, en estos museos no suele haber mención alguna a periodos especialmente "pródigos" en materia de tortura y malos tratos como la dictadura de Franco. 


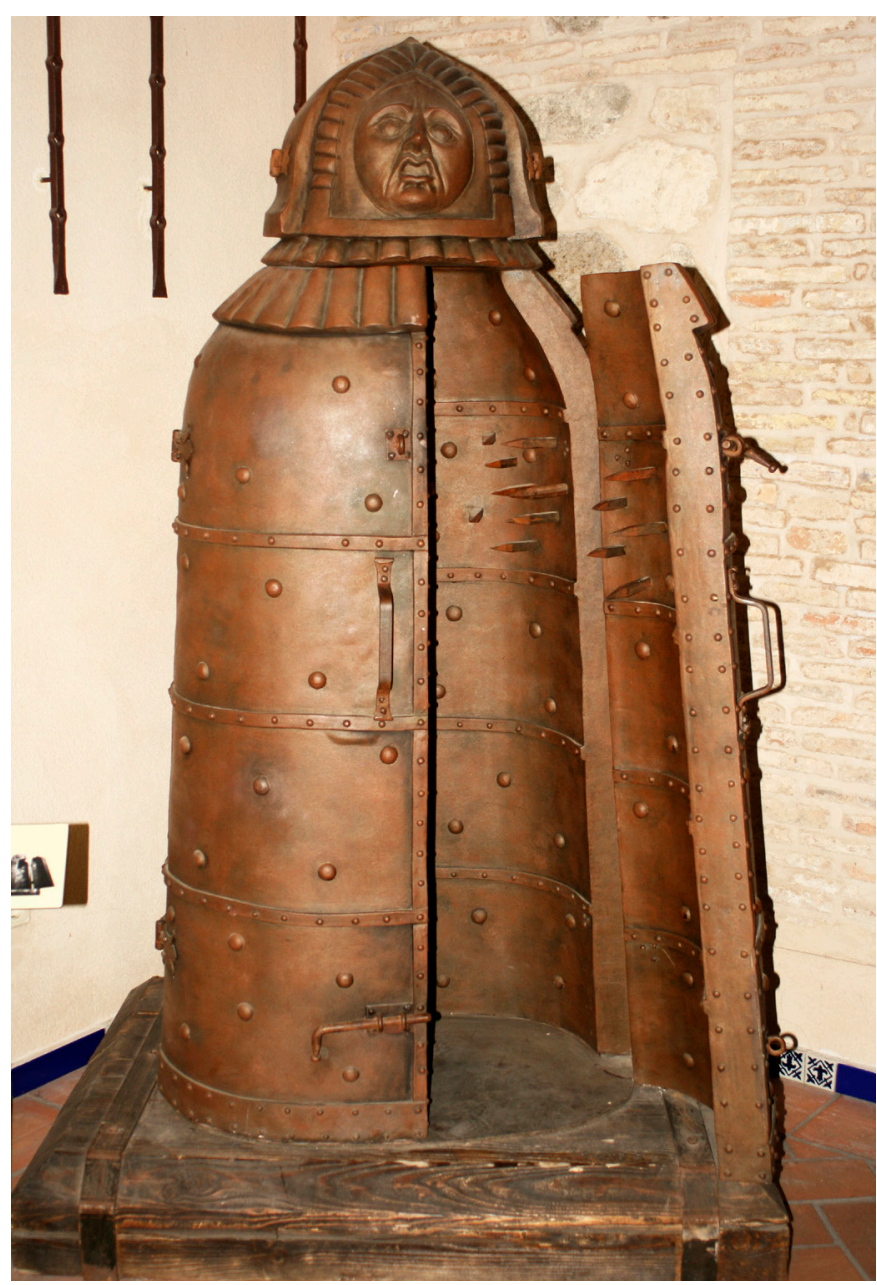

Doncella de hierro en el Museo de la Tortura de Toledo | foto Angel Aroca Escáme

Los museos de la tortura que pueblan los centros históricos de pueblos y ciudades de España suelen centrar su atención en la Inquisición española (1478-1834). Las mazmorras, los instrumentos de tortura -como el "potro" o el "aplastapulgares"- y los maniquíes de cuerpos ensangrentados nos remiten a un pasado remoto, teatralizado de forma pintoresca, como queriendo profundizar en la brecha histórica entre el ayer y el hoy. Si se expone un garrote vil, seguramente será para mostrar su uso como simple herramienta de ejecución de "criminales" en un pasado lejano, sin referencia alguna a su empleo como parte de la práctica de la pena de muerte en España hasta 1974. Además, la parafernalia carnavalesca de estos "museos de la tortura" no guarda relación alguna con la cruda realidad de la tortura en la sociedad contemporánea. Una realidad en la que objetos cotidianos como una bañera, una bolsa de plástico, un listín telefónico o incluso un bolígrafo son los verdaderos instrumentos para el tormento que se emplean en comisarías y cárceles (Etxeberria, Beristain y Pego, 2017: 168-184).

Los "museos de la tortura" no tienen por qué ser vistos como problemáticos en sí mismos. El problema es que son la única representación de la tortura en la oferta patrimonial y turística del país. Y ello se debe a una clara voluntad de olvido. Concretamente un olvido en forma de "retorno" o en clave de "tradicionalismo" como diría Marc Augé (González Calleja 2013, 137; originalmente, en Augé 1998). Un olvido en el cual se expone de forma aparatosa y exaltada un pasado anterior, haciéndolo brillar con un fulgor especial, con el objetivo de cegar toda posible visión crítica sobre el pasado más cercano o incluso sobre el presente.

En los museos de la tortura en España no cabe hablar de informes como el del Relator Especial de la ONU Theo van Boven sobre la cuestión de la tortura en España (ONU 2004) o el documento Sal en la herida de Amnistía Internacional (2007). En los museos de la tortura en España tampoco se recogen testimonios de personas torturadas.

De hecho, casi ningún espacio de tortura en España ha sido objeto de musealización (Sánchez-Carretero 2013; Oliver Olmo 2020). Lugares como la Real Casa de Correos en la Puerta del Sol, actual sede del Gobierno de la Comunidad de Madrid y un conocido espacio de detención y tortura de militantes antifranquistas a lo largo de la dictadura y la transición, son verdaderos "lugares de olvido" (sensu Boyarin 1989) o "lugares de negación" (Míguez Macho 2018). Algo similar se podría decir del Palacio de la Cumbre en San Sebastián, en cuyos sótanos agentes de la Guardia Civil torturaron e hicieron desaparecer a los militantes de ETA Joxean Lasa y Joxi Zabala en 1983, tal como después se demostró en sede judicial. 


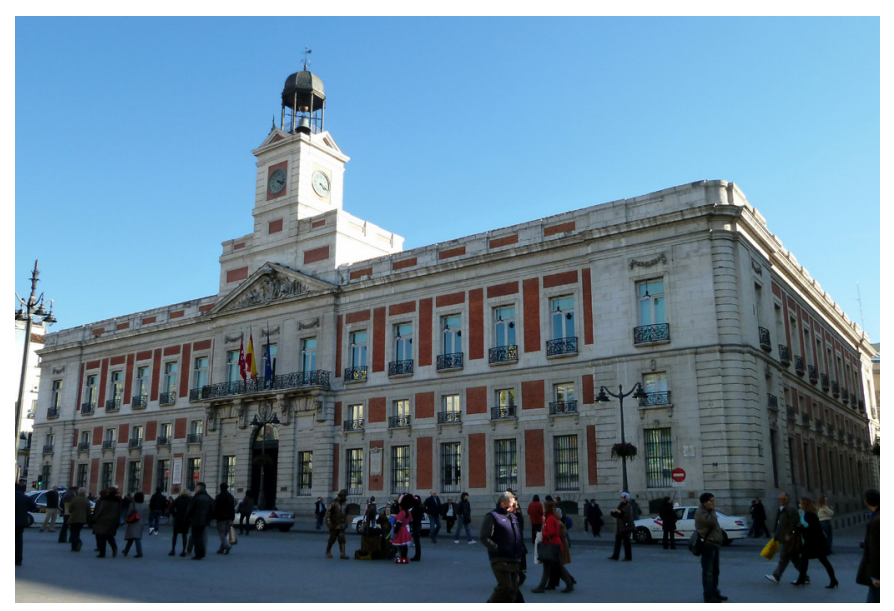

Real Casa de Correos en la Puerta del Sol de Madrid | foto Luis García (Zaqarbal)

Éstos son sólo dos ejemplos de centros de detención y tortura que aún hoy son propiedad del Estado y que, por lo tanto, podrían ser debidamente señalizados y visibilizados como lo que son: los verdaderos museos de la tortura en España. Mientras tanto, los "otros" museos de la tortura seguirán aportando el toque de "turismo oscuro" ideal a todo y toda turista que se precie, entre la visita al castillo y el paseo por la muralla del pueblo, justo antes de entrar a comer un buen cochinillo o un cordero bien tierno en el mesón de la plaza.

\section{BIBLIOGRAFÍA}

- Amnistía Internacional (2007) España: Sal en la herida. La impunidad efectiva de agentes de policía en casos de tortura y otros malos tratos. Londres: Secretario Internacional. Disponible en: https://www.amnesty.org/es/documents/ eur41/006/2007/es/ [Consulta: 03/11/2021]

- Augé, M. (1998) Las formas del olvido. Barcelona: Gedisa, 1998

- Boyarin, J. (1989) Un lieu de l'oubli: le Lower East Side des Juifs. Communications, n. ${ }^{\circ} 49$, pp. 185-193

- Consejo de Europa (1950) Convenio Europeo de Derechos Humanos. Estrasburgo: Tribunal Europeo de Derechos Humanos. Disponible en: https://www.echr.coe.int/documents/ convention_spa.pdf [Consulta: 03/11/2021]

- Etxeberria, F., Martín Beristain, C. y Pego, L. (2017) Informe final. Proyecto de investigación de la tortura y malos tratos en el País Vasco entre 1960-2014. Vitoria-Gasteiz: Secretaría General de Derechos Humanos, Convivencia y CooperaciónGobierno Vasco

- González Calleja, E. (2013) Memoria e historia. Vademécum de conceptos y debates fundamentales. Madrid: Los Libros de la Catarata

- Míguez Macho, A. (2018) Un pasado negado. Lugares de violencia y lugares de memoria del golpe, la guerra civil y el franquismo. Confluenze. Rivista di Studi Iberoamericani, vol. 10, n. ${ }^{\circ}$ 2, pp. 127-151

- Oliver Olmo, P. (coord.) (2020) La tortura en la España contemporánea. Madrid: Los Libros de la Catarata

- ONU [Organización de las Naciones Uindas] (1984) Convención contra la Tortura y Otros Tratos o Penas Crueles, Inhumanos o Degradantes. Nueva York: Alto Comisionado de las Naciones Unidas para los Derechos Humanos. Disponible en: https://www.ohchr.org/Documents/Professionallnterest/ cat_SP.pdf [Consulta: 03/11/2021]

- ONU [Organización de las Naciones Uindas] (2004) Los derechos civiles y políticos, en particular las cuestiones relacionadas con la tortura y la detención. Informe del Relator Especial sobre la cuestión de la tortura, Theo van Boven. Nueva York: Comisión de Derechos Humanos, 2004. Disponible en: https://www.nodo50.org/tortura/informes/onu/ INFORMERELATORTHEOVANBOVEN6.02.04.htm [Consulta: 03/11/2021]

- Sánchez-Carretero, C. (2013) Patrimonialización de espacios represivos: en torno a la gestión de los patrimonios incómodos en España. En: Ortiz García, C. (coord.) Lugares de represión, paisajes de la memoria: aspectos materiales y simbólicos de la cárcel de Carabanchel. Madrid: Los Libros de la Catarata, pp. 28-41 